\section{REFERENCES}

1 Bush A, Chodhari R, Collins N, et al. Primary ciliary dyskinesia: current state of the art. Arch Dis Child 2007; 92: 1136-1140.

2 Lie H, Ferkol T. Primary ciliary dyskinesia: recent advances in pathogenesis, diagnosis and treatment. Drugs 2007; 67: 1883-1892.

3 Pifferi M, Cangiotti AM, Ragazzo V, et al. Primary ciliary dyskinesia: diagnosis in children with inconclusive ultrastructural evaluation. Pediatr Allergy Immunol 2001; 12: 274-282.

4 Pifferi M, Caramella D, Cangiotti AM, et al. Nasal nitric oxide in atypical primary ciliary dyskinesia. Chest 2007; 131: 870-873.

5 Pifferi M, Montemurro F, Cangiotti AM, et al. Simplified cell culture method for the diagnosis of atypical primary ciliary dyskinesia. Thorax. 2009; 64: 1077-1081.

6 Duriez B, Duquesnoy P, Escudier E, et al. A common variant in combination with a nonsense mutation in a member of the thioredoxin family causes primary ciliary dyskinesia. Proc Natl Acad Sci USA 2007; 104: 3336-3341.

7 Schwabe GC, Hoffmann K, Loges NT, et al. Primary ciliary dyskinesia associated with normal axoneme ultrastructure is caused by DNAH11 mutations. Hum Mutat 2008; 29: 289-298.
8 Piacentini GL, Bodini A, Peroni D, et al. Nasal nitric oxide for early diagnosis of primary ciliary dyskinesia: practical issues in children. Respir Med 2008; 102: 541-547.

9 Bartoloni L, Blouin JL, Pan Y, et al. Mutations in the DNAH11 (axonemal heavy chain dynein type 11) gene cause one form of situs inversus totalis and most likely primary ciliary dyskinesia. Proc Natl Acad Sci USA 2002; 99: 10282-10286.

10 Supp DM, Witte DP, Potter SS, et al. Mutation of an axonemal dynein affects left-right asymmetry in inversus viscerum mice. Nature 1997; 389: 963-966.

11 UniProt Knowledge Database. www.expasy.org/uniprot Date last updated: February 17, 2010.

12 Berkeley Drosophila Genome Project. www.fruitfly.org/seq_tools/ splice.html Date last updated: November 6, 2008.

13 PolyPhen, prediction of functional effect of human nsSNPs. http:// genetics.bwh.harvard.edu/pph Date last updated: February 24, 2010.

14 The Human Gene Mutation Database at the Institute of Medical Genetics in Cardiff. www.hgmd.cf.ac.uk/ac/index.php Date last updated: February 16, 2010.

\title{
Exhaled nitric oxide in contrasting population samples of Finnish and Russian Karelia
}

\section{To the Editors:}

Considerable differences between countries in prevalence of asthma and atopy have been reported that show association between increased risk and western lifestyle and urbanisation [1]. The allergy substudy of the National FINRISK Study and the Karelia Allergy Study, both carried out in North Karelia, Finland, and the Pitkäranta region, Russia, revealed a significantly higher occurrence of asthma and atopic diseases on the Finnish side, the disparity showing a growing generational trend [2,3]. Despite the geographical neighbourhood, the sensitisation rates for airborne allergens, determined with skin-prick tests or specific immunoglobulin (Ig)E levels, were four-fold in children and two- to three-fold in adults from Finnish Karelia, which may be attributed to the higher level of urbanisation, western type of living conditions and poor microbial environment [4].

Exhaled nitric oxide (eNO) is a noninvasive marker of airway inflammation, and is usually increased in patients with asthma. eNO is strongly associated with atopy in populationbased studies [5-9]. Also, many other factors, such as sex and anthropometric dimensions, tobacco smoking and acute respiratory infections, have been reported to influence eNO levels. To date, there are no reports of the differences in eNO levels between populations with different degrees of urbanisation and living conditions. We postulated that different atopic prevalences between Finnish and Russian Karelia might be reflected in the levels as well as the determinants of eNO. Therefore, in the Karelia Allergy follow-up study in 2007, we measured eNO levels in adult population samples from Finnish and Russian Karelia, and investigated the effect of several demographic, disease-related and environmental factors.
Random samples of adults aged 25-54 yrs were drawn from the population register and electoral rolls in Finnish and Russian Karelia, with participation rates of $61 \%(n=727)$ and $48 \%(n=312)$, respectively. The study included a self-administered questionnaire containing data on demographic, home and living factors and disease history of asthma and atopy, an assay of total and specific IgE against common airborne allergens (birch, mugwort, timothy grass, cat, dog, horse, Cladosporium herbarum and Dermatophagoides pteronyssinus; Phadiatop, UniCAP 1000, Pharmacia Upjohn, Uppsala, Sweden) and measuring eNO by using a portable electrochemical analyser (Niox Mino, Aerocrine AB, Sweden). This device measures eNO during a 10-s exhalation with a constant flow of $50 \mathrm{~mL} \cdot \mathrm{s}^{-1}$, according to the international recommendations. All the measurements were performed during winter, outside the pollen season. Altogether 691 subjects (females $53 \%$ ) in Finland and 305 subjects (females 61\%) in Russia had successful eNO measurements. The mean age was similar in the study samples (40 versus $40 \mathrm{yrs}$, respectively). eNO data were $\log _{10}$ transformed for statistical analysis. The MannWhitney U-test, t-test and linear regression analysis were used for univariate analyses, and general linear methods were used to study the independent effects of the variables in multivariate settings. The study was approved by the coordinating ethics committee of the Helsinki and Uusimaa District Hospital, Finland.

The current overall results concerning higher prevalence of reported asthma, atopic diseases and specific IgE responses in North Karelia, Finland, compared with those observed in the Pitkäranta region, Russia, are described elsewhere ( $T$. Laatikainen, personal communication). The subjects participating in the eNO study in Finnish Karelia showed a higher 
prevalence of history of asthma (9\%), allergic rhinitis $(30 \%)$ and positive $\operatorname{IgE}$ responses to respiratory allergens (29\%) than the subjects participating in the eNO study in Russian Karelia $(1 \%, 6 \%$ and $21 \%$, respectively). Fewer of the subjects in Finnish Karelia smoked (32\% versus $61 \%$ ).

The eNO levels in Finnish North Karelia were significantly higher than in Russian Karelia, the median (interquartile range) eNO being $12(8-17)$ and $11 \quad(7-14) \quad(p<0.001)$, respectively. Males had higher levels than females in Finland (13 (8-19) versus 11 (8-17), $\mathrm{p}=0.028)$, but tended to have lower levels than females in Russia (10 (6-14) versus 11 (8-14), $\mathrm{p}=0.079$ ). In order to assess determinants of eNO in both study populations, possible explanatory variables showing significant associations with eNO in univariate analyses were entered stepwise (forward selection method) in the multiple regression analysis. The results of the models consisting of statistically significant independent factors, as well as the list of factors showing significant associations with eNO in univariate but not in multivariate analyses, are shown in table 1 . Current smoking, specific IgE levels for the mixture of airborne allergens as a continuous variable, recent respiratory infection within 2 weeks, and the history of asthma were all independent factors associated with eNO levels both in Finnish and in Russian Karelia. The fraction of eNO increased with increasing levels of specific IgE, but, independently of that, the subjects with a history of asthma had significantly higher levels of eNO. On average, current smoking reduced eNO by $37 \%$, and recent respiratory infection within 2 weeks increased levels by $21 \%$. In addition, female sex was significantly associated with lower eNO levels in the Finnish sample $(p=0.002)$ and, after adjusting for smoking, a similar trend was also observed in Russia $(p=0.064)$. Interestingly, living in the countryside during childhood was independently associated with lower eNO levels in Finnish Karelia $(p=0.044)$, and was almost significant in Russia $(p=0.053)$. None of the regression coefficients in table 1 were significantly different between the population samples (data not shown).

The current results showed that, despite the contrasting environments, prevalence of atopic manifestations as well as different levels of eNO, the determinants of eNO were very similar in the adult population samples of Finnish and Russian Karelia. The main factors (smoking, IgE levels and recent respiratory infection) had remarkably similar coefficients in the regression models. The only exception was the estimate for the association between eNO and reported history of asthma, which showed a somewhat (albeit not statistically significantly) stronger effect in Russian Karelia. This may be due to the small number of cases, or because cases with mild asthma were not equally often reported as in the Finnish sample. The observation that environmental factors and the prevalence of atopy do not markedly change the associations of eNO has important implications. First, the clinical interpretation of increased eNO is likely to be the same in populations with different environmental backgrounds. Secondly, the finding encourages meta-analyses by combining previously published population datasets. Such databases could be the basis for tools to calculate individualised reference values more widely.

A population-based study of twins suggests that genetic effects account for most of the variation in eNO fraction, and that environmental factors have a minor role [10]. Although both study populations represent Caucasian ethnicity, genetic factors may contribute to the differences between eNO levels in Finnish and Russian Karelia, due to the repopulation of the Russian Karelia in the 1950s, after the war. However, the higher prevalence of atopy and asthma, and the lower occurrence of smoking in Finland are more likely explanations for the difference. In the Finnish population sample, the observation that living in the countryside during childhood was related to lower eNO levels gives further support to the concept that the higher prevalence of atopic manifestations is related to urbanisation, western lifestyle and different microbial environments $[1,4]$. A similar trend also emerged from the Russian data.

Previous population studies have shown conflicting results about the relationship between eNO and reported asthma [5-9]. In both of the current study populations, the history of asthma was associated with increased eNO levels, independently of specific IgE levels as a marker of atopy. This may be restricted to the adult population, since in a population sample of children from the same area we could not find any

\begin{tabular}{|c|c|c|c|c|}
\hline \multirow[t]{2}{*}{ Factor } & \multicolumn{2}{|c|}{ Finland } & \multicolumn{2}{|c|}{ Russia } \\
\hline & $\beta$ & p-value & $\beta$ & $p$-value \\
\hline Constant & $1.119 \pm 0.076$ & $<0.001$ & $0.903 \pm 0.133$ & $<0.001$ \\
\hline Respiratory infection within 2 weeks & $0.051 \pm 0.017$ & 0.003 & $0.049 \pm 0.017$ & 0.003 \\
\hline Female sex & $-0.077 \pm 0.024$ & 0.002 & $-0.049 \pm 0.026$ & 0.064 \\
\hline History of asthma & $0.097 \pm 0.043$ & 0.023 & $0.268 \pm 0.119$ & 0.017 \\
\hline Childhood home in the countryside & $-0.049 \pm 0.024$ & 0.044 & $-0.047 \pm 0.024$ & 0.053 \\
\hline
\end{tabular}

Data are presented as mean \pm SE. IgE: immunoglobulin E. \#: Factors tested but found not to be significant in either population samples: history of allergic rhinitis, history of atopic dermatitis, age, total IgE. ": The level of serum specific IgE against a mixture of common airborne allergens (birch, mugwort, timothy grass, cat, dog, horse, Cladosporium herbarum and Dermatophagoides pteronyssinus) 
independent association between asthma and eNO [6]. Accordingly, other studies with paediatric population samples have failed to demonstrate the relationship. There are cogent data on the influence of smoking and respiratory infections on eNO levels, but reports regarding the effect of sex have been inconsistent $[5,7,8]$. Our data support the concept that, in adults, sex is a variable that should be taken into account so that routine eNO measurements could be interpreted appropriately.

We conclude that although eNO levels in Finnish Karelia were higher than in Russia, the determinants of eNO were remarkably similar in these two population samples with contrasting socioeconomic environments and prevalence of atopy. The clinical significance of increased eNO is likely to be independent of environmental factors in the population.

\section{L.P. Malmberg*, T. Laatikainen", L. von Hertzen*, M.J. Mäkelä*, E. Vartiainen ${ }^{\#}$ and T. Haahtela*}

*Dept of Allergy, Skin and Allergy Hospital, Helsinki University Central Hospital, and "Dept of Epidemiology and Health Promotion, University of Helsinki, Helsinki, Finland.

Correspondence: L.P. Malmberg, Dept of Allergy, Helsinki University Central Hospital, PO Box 160, 00029 HUS, Helsinki, Finland. E-mail: pekka.malmberg@hus.fi

Support Statement: The Karelia Allergy Study Programme has been supported by grants from the Finnish Academy, Helsinki University Hospital and Juselius Foundation.

\section{REFERENCES}

1 von Mutius E. The environmental predictors of allergic disease. J Allergy Clin Immunol 2000; 105: 9-19.

2 Vartiainen E, Petäys T, Haahtela T, et al. Allergic diseases, skin prick test responses, and IgE levels in North Karelia, Finland, and the Republic of Karelia, Russia. J Allergy Clin Immunol 2002; 109: 643-648.

3 von Hertzen L, Mäkelä MJ, Petäys T, et al. Growing disparities in atopy between the Finns and the Russians: a comparison of 2 generations. J Allergy Clin Immunol 2006; 117: 151-157.

4 von Hertzen L, Laatikainen T, Mäkelä M, et al. Infectious burden as a determinant of atopy - a comparison between adults in Finnish and Russian Karelia. Int Arch Allergy Immunol 2006; 140: 89-95.

5 Olin A-C, Rosengren A, Thelle DS, et al. Height, age and atopy are associated with fraction of exhaled nitric oxide in a large adult general population sample. Chest 2006; 130: 1319-1325.

6 Malmberg LP, Petäys T, Haahtela T, et al. Exhaled nitric oxide in healthy nonatopic school-aged children - determinants and heightadjusted reference values. Pediatr Pulmonol 2006; 41: 635-642.

7 Travers J, Marsh S, Aldington S, et al. Reference ranges for exhaled nitric oxide derived from a random community survey of adults. Am J Respir Crit Care Med 2007; 176: 238-242.

8 Taylor DR, Mandhane P, Greene JM, et al. Factors affecting exhaled nitric oxide measurements: the effect of sex. Respiratory Research 2007; 8: 82.

9 van Asch CJ, Balemans WA, Rovers MM, et al. Atopic disease and exhaled nitric oxide in an unselected population of young adults. Ann Allergy Asthma Immunol 2008; 100: 59-65.

10 Lund MB, Kongerud J, Nystad W, et al. Genetic and environmental effects on exhaled nitric oxide and airway responsiveness in a population-based sample of twins. Eur Respir J 2007; 29: 292-298. 